and a little above the wound was dowelled and fastened by means of two strong wires, so that by the withdrawal of the wires the wound could be easily dressed. But owing to the great pain caused by the limb being brought into a straighter position, which the lad described as " unbearable," it was deemed advisable to remove it, and to support the limb as well as possible by means of pillows.

The patient became so restless that the thin skin-flap gave way. The discharge became thick and healthy, and fine healtby granulations sprang up. The health greatly improved, and the lad took his food well, slept well, and by means of gradual and gentle extension the limb assumed a much better position. The case progressed satisfactorily for a considerable time, but six months after the operation the patient died of kidney disease. On examining the joint after death the wound was found entirely healed, and there was good motion. The shortening was four and a half inches.

In reviewing the history of this case it would appear that if rest and extension had been fairly tried and carried out from the very first, the lad would never have been in the sad plight he presented on admission. Mr. Woods has now under his care a patient with incipient hip-joint disease, in whom on admission there was intense pain at the kuee, whick the patient could not straighten. He was placed under chloroform, the knee straightened, a well-adapted splint placed on the thigh, extension applied, and a swelling which was observed in the region of the joint evacuated by means of the pneumatic aspirator, and now the pain in the knee is altogether relieved. The patient bas good nights, and is gaining strength daily. There can be no doubt that where rest and extension can be obtained at the onset, this very insidious disease may, in a great number of cases, be brought into something like subjection. Rest and extension are now looked upon as remedial agents of no small value; they have been long tried for injuries, but until late years have not received that attention from surgeons which they so greatly merit. That large numbers of joints are by these means annually saved is certain, and cases of hip.joint disease terminating in suppuration are now less frequent than formerly.

\section{CROYDON UNION INFIRMARY.}

\section{DISSECTING ANEURISM OF AORTA RUPTURING INTO} LEFT PLEURAL CAVITY.

(Under the care of Mr. HoksLer.)

For the notes of the following case we are indebted to Mr. Herbert J. Ilott, M.B., house-surgeon to the Croydon General Hospital.

H. H-, aged fifty-six, inmate of the Croydon Union, who was employed on odd jobs at the infirmary, on Saturday afternoon, March 13th, was assisting two other men to place a thirty-six gallon cask of beer on a stand. When they had accomplished their task, the patient said he feared he had strained bimself. He then walked into the kitchen, which was close at hand, and sat down. He complained of pain in the region of the heart and in the left shoulder. His face soon became very flushed, and a copious sweat appeared on it, accompanied by trembling of the limbs. He remained in the kitchen about ten minutes, then rose and walked with assistance across the yard to one of the wards, distant about twenty yards. After sitting on one of the beds a short time his breathing became hurried, and his general aspect distressed. When seen by Mr. Horsley in the evening he was lying on bis back, and had noisy and laboured breathing. He complained of great pain over the left side of the chest. On auscultation a loud systolic nurmur was heard below the lett nipple, extending to the axilla. It was then thought that he might have ruptured some of the chordæ tendinex of the mitral valve. The patient died that night about one o'clock on the 14th, having survived the accident about ten bours.

Post-mortem by Dr. ILOTw, on March 15th.-Body spare. A small movable tumour was detected in the abdominal wall to the left of the mesial line; this on removal was found to be a nævoid tumour encapsulated, consisting of cavernous spaces filled with venous blood, a firm solid substance intervening. There was a large scrotal hernia, as big as a child's head, on the right side; this contained several coils of small intestine. The sac was much thickened with old organised deposit on the interior; the external and internal atudominal rings were closely approximated, the opening admitting three fingers. 'I'his hernia had always been readily reduced. Thorax: Left pleural cavity filled with dark loosely coagulated blood, enough to fill half an ordinary washhand-basin; no blood in right pleura; old adhesions on left side; no blood in pericardium. Heart, lungs, and large vessels removed en masse. On clearing away blood from the aorta. and oesophagus, a rent of the coats of the aorta was found just below the origin of the left subclavian artery, from the arch extending for an inch and a half through the external coat in the axis of the vessel; at the upper border of this opening was a transverse rupture of the inner and middle eonts, about half an inch long, across the upper half of the calibre of the vessel. On opening the beart and aorta, the left ventricle was found considerably hypertrophied, the mitral valve and its chordæ tendineæ much thickened; in the substance of the anterior cusp was a firm bony plate; the aortic sigmoids were thickened; the aorta, especially the arch, was considerably dilated; its coats were highly atheromatous. The rent above-mentioned was seen on its inner aspect. On further examination it was found that the blood had forced its way between the coats of the aorta from the point just mentioned as far as the point of bifurcation of the abdominal aorta into the common iliacs. Here a second laceration was found, running transversely through the inner coat, about a quarter of an inch long. The blood had passed between the points of rupture through a false channel on posterior and inner aspects of the vessel, between the external and internal and middle coats. A large, soft, black clot occupied the inferior vena cava and the iliac veins. Liver normal. Kidneys very small, hard, and tough, with small cysts here and there in cortex; capsule not adberent. Spleen normal. Lungs gorged at bases, otherwise normal.

Remarks.-The course of this case seems to have been, first, rupture of the internal coat of the aorta, at a spot weakened by atheromatous degeneration, during violent exertion, when the blood-pressure in the arch would beincreased considerably above the normal by the contractions of an hypertrophied left ventricle; secondly, the formation of a dissecting aneurism, which caused so much strain on the external coat of the aorta that it gave way at the point where it was most exposed to pressure; and, thirdly, the blood gradually filling up the pleural cavity induced asphyxia by pressure on the lungs. The pressure of the distended aorta on the lower parts of the inferior cava seems to have occasioned thrombosis in this vessel and in the iliac veins, which, had the patient lived longer, might bave sbown itself by signs of impeded return of blood from the lower extremities. The diagnosis was obscure, as the symptoms were ill-defined, pointing merely to some grave injury to the circulatory apparatus. Anctber interesting point is, the length of time the man survived the accident and his capability of walking about after so severe a lesion.

\section{antedical Sorieties.}

\section{ROYAL MEDICAL AND CHIRURGICAL SOCIETY.}

THe ordinary meeting of this Society was held on the 25th inst., the President, Sir James Paget, in the chair. Some interesting papers were read, notably one by Mr. Gay, on a novel treatment of nasal lupus-namely, by excision, combined with a plastic operation. Mr. Lawson Tait's contribution on a case of congenital deficiency of the peritoneum was read in abstract only; and the Society adjourned till October 12th, several papers remaining on the list, in. cluding one by Dr. Dickinson, on the Pathology of Chorea, and one by Dr. Semple on Croup and Diphtheria.

The first paper read was on the "Treatment of Nasal Lupus by Excision," by Mr. JoHN GAY. Its object was to show that lupus exedens is a topically malignant form of ulceration; and that the alleged cures of this affection by constitutional means are probably due either to errors in diagnosis or to the inclusion under the generie term " lupus" 